\title{
Recria intensiva em confinamento como estratégia de manejo em bovinos de corte - revisão de literatura
}

\author{
Intensive rearing in confinement as a management strategy in beef cattle - literature review \\ La cría intensiva en confinamiento como estrategia de manejo en el ganado de carne - revisión de la
}

\section{literatura}

Recebido: 28/12/2021 | Revisado: 04/01/2022 | Aceito: 15/01/2022 | Publicado: 17/01/2022

\author{
Igor José Carvalho Batistelli \\ ORCID: https://orcid.org/0000-0002-8095-4036 \\ Universidade Federal de Mato Grosso, Brasil \\ E-mail: igorbatistelli@hotmail.com \\ Juliana Carla de Oliveira Rodrigues Batistelli \\ ORCID: https://orcid.org/0000-0002-7066-5169 \\ Universidade Federal de Mato Grosso, Brasil \\ E-mail: jucarlarodrigues@ hotmail.com \\ Bruno Luiz Bess \\ ORCID: https://orcid.org/0000-0003-4618-7133 \\ Universidade Federal de Mato Grosso, Brasil \\ E-mail: comercial.sinop@nutralimt.com.br \\ Flávio Luiz de Menezes \\ ORCID: https://orcid.org/0000-0002-4009-9338 \\ Universidade Federal de Mato Grosso, Brasil \\ E-mail: flm.zootecnista@gmail.com \\ Kamila Andreatta Kling de Moraes \\ ORCID: https://orcid.org/0000-0001-9864-5322 \\ Universidade Federal de Mato Grosso, Brasil \\ E-mail: kamilandreatta@gmail.com \\ Eduardo Henrique Bevitori Kling de Moraes \\ ORCID: https://orcid.org/0000-0001-8634-6675 \\ Universidade Federal de Mato Grosso, Brasil \\ E-mail: eduardobkm@gmail.com
}

\begin{abstract}
Resumo
Esta revisão de literatura tem como objetivo explanar questões sobre a estratégia de recria intensiva de bezerros de corte de bezerros confinados no momento da recria, principalmente no período de seca, com destaque na intensificação da recria e redução da pressão de pastejo. No Brasil, o sistema de produção predominante na a pecuária de corte, é o sistema extensivo que no qual a base é principalmente em regime de pastagens tropicais e temperadas, ainda com dificuldade de transferência de tecnologia por parte dos técnicos, as informações ao produtor do uso de suplementação alimentar e sal mineral. Nesse cenário, não há investimento substancial, e simultaneamente outro fator a ser considerado a época da seca, em que os animais não conseguem obter resultados positivos com ganhos de peso razoável, ou até mesmo a sua própria manutenção de desempenho corporal. Para que a terminação ocorra de maneira mais rápida ao longo de todo o processo, tem se utilizado a intensificação de bezerros em confinamento na recria, devido esta categoria, apresentar uma exigência nutricional menor, portanto, muitas vezes não priorizada a suplementação e monitoramento da mesma, além de no momento da adaptação ao desmame para a passagem de sua primeira seca a pasto ser substituída pelo resgate. Então a estratégia alimentar de recria proposta favorece o sistema como todo como forma de planejamento e otimização de resultados e redução da taxa de lotação em momentos mais críticos.
\end{abstract}

Palavras-chave: Desempenho ponderal; Produção animal; Ruminantes; Nutrição animal.

\begin{abstract}
This literature review aims to explain questions about the intensive rearing strategy of beef calves confined at the time of rearing, especially during the dry season, with emphasis on the intensification of rearing and reduction of grazing pressure. In Brazil, the predominant production system in beef cattle raising is the extensive system in which the base is mainly in tropical and temperate pastures, still with difficulty for technicians to transfer technology, information to the producer. use of food supplementation and mineral salt. In this scenario, there is no substantial investment, and simultaneously another factor to be considered is the dry season, in which the animals are unable to obtain positive results with reasonable weight gains, or even their own maintenance of body performance. In order for the termination
\end{abstract}


to occur more quickly throughout the entire process, the intensification of feedlot calves in the rearing has been used, as this category presents a lower nutritional requirement, therefore, supplementation and monitoring is often not prioritized, as well as at the time of adaptation to weaning for the passage of its first drought to pasture to be replaced by rescue. So, the proposed breeding food strategy favors the system as a whole as a way of planning and optimizing results and reducing the stocking rate at more critical moments.

Keywords: Weight performance; Animal production; Ruminants; Animal nutrition.

\section{Resumen}

Esta revisión de la literatura tiene como objetivo explicar preguntas sobre la estrategia de cría intensiva de terneros de carne confinados en el momento de la cría, especialmente durante la estación seca, con énfasis en la intensificación de la cría y la reducción de la presión del pastoreo. En Brasil, el sistema de producción predominante en la ganadería de carne es el sistema extensivo en el que la base es principalmente pastos tropicales y templados, aún con dificultad para que los técnicos transfieran tecnología, información al productor, uso de complementos alimenticios y sal mineral. En este escenario, no hay una inversión sustancial, y simultáneamente otro factor a considerar es la estación seca, en la que los animales no pueden obtener resultados positivos con ganancias de peso razonables, o incluso su propio mantenimiento del rendimiento corporal. Para que la terminación se produzca más rápidamente a lo largo de todo el proceso, se ha utilizado la intensificación de los terneros de engorde en la cría, ya que esta categoría presenta un menor requerimiento nutricional, por lo que muchas veces no se prioriza la suplementación y el seguimiento. el tiempo de adaptación al destete para el paso de su primera sequía al pasto para ser reemplazado por rescate. Por tanto, la estrategia de alimentación de cría propuesta favorece al sistema en su conjunto como una forma de planificar y optimizar resultados y reducir la carga ganadera en momentos más críticos.

Palabras clave: Rendimiento de peso; Producción animal; Rumiantes; Nutrición animal.

\section{Introdução}

O conhecimento sobre o crescimento da população e demanda na produção alimentícia tornaram fatores determinantes, no qual foi possível evitar oscilações e desabastecimento indesejados para produção mundial de alimentos. O comércio de carnes no mundo tem grande participação no orçamento alimentício da população desde muitos anos, trata-se de um meio com grande diversidade, sendo $70 \%$ direcionado ao consumo de carne de suínos e aves, $25 \%$ é destinado ao consumo de carne bovina e $5 \%$ por carnes de origem caprina e ovina, porém consumidores da carne bovina tem procurado alternativas para substituir essa proteína devido ao aumento dos preços (Santos e Borges, 2019).

Apesar dos impactos mundiais causados pela pandemia do COVID-19, o setor de exportação de carne bovina ganhou destaque em março de 2020, quando comparado ao mesmo período do ano anterior. Mas a incerteza que ocorreu desde a descoberta do vírus gerou bastante desconforto e desequilíbrio demonstrado o consumo per capita foi de 36,39 kg/ano (ABIEC 2021) em toda a cadeia produtiva, no qual foi necessário reajuste no manejo dos animais (Malafaia et al., 2020; ABIEC, 2020).

A estagnação dos índices reprodutivos ainda é um fato, isso acontece devido principalmente ao tempo de desmame do animal, que ocorre geralmente entre os sete e oito meses após o nascimento, ou seja, tempo de cria e até doze meses na recria que vai do desmame até o começo da terminação. O aumento da tecnologia e técnicas disponíveis para o manejo nutricional dos bovinos devem ser utilizados como aliados nos índices de reprodução dos animais, podendo cair para noventa dias o desmame precoce, sem que haja nenhum risco ou prejuízo para a cria, existindo estratégias nutricionais e de manejo para resolver o atraso no desenvolvimento ponderal do animal (Pinto e Millen, 2018; Silveira, et al., 2021).

O confinamento surgiu como meio para viabilizar a compra e venda dos animais nos períodos de safra e entressafra respectivamente, na fase de recria os animais são alimentados em uma dieta total estimada, a fim de acelerar o ciclo. Quando chegam na fase de terminação, os animais recebem volume maior dos concentrados para que não ocorra o rebaixamento do peso dos mesmos, nesse período o desejável é que o animal realize deposição muscular reduzida e simultaneamente uma maior deposição de tecido adiposo na carcaça (Delevatti, et al., 2019; Nascimento, 2021).

O semiconfinamento o animal tem disponível a maior parte da dieta em pastos convencionais, mas na fase final de engorda, são oferecidos cochos com concentrados a fim de acelerar o ganho de peso. Já é discutida a questão dos custos do confinamento e semiconfinamento, onde a segunda opção requer menos investimentos para implementação e garante bastante 
eficiência no resultado final (Siqueira, 2018).

Diante do exposto, o objetivo da realização dessa revisão de literatura tem como propósito elucidar questões sobre a estratégia de sequestro de bezerros no momento da recria, principalmente no período de seca, com enfoque na intensificação da recria e redução da pressão de pastejo.

\section{Metodologia}

Esta revisão sistemática foi baseada em livros, artigos científicos e ensaios experimentais, publicados em bases eletrônicas de dados (Scielo, Google Scholar, Scopus, Science Direct e Web of Sciences). Foram selecionados e avaliados trabalhos publicados no Brasil e no mundo, sobre estratégias de manejo e nutricional, no período de recria de bovinos de corte com enfoque na intensificação do sistema.

Com finalidade do assunto de explorar o desenvolvimento ao longo dos anos foram buscados trabalhos científicos até o ano de 2020 com palavras chave de "Beef cattle", "Recria intensiva" "Feedlot" e "Calf fed".

\section{Revisão de literatura}

\section{Panorama da Pecuária Brasileira}

O Brasil é o segundo maior produtor e o quarto maior consumidor de carne bovina do mundo, no qual colocou o setor da pecuária seja uma das atividades do agronegócio mais importante do país. No ano de 2020 o PIB (Produto Interno Bruto) do setor registrou um crescimento de 20,8\%, somando 747,05 bilhões de reais isso representa a força do setor pecuário na economia brasileira. Com um rebanho de 187,55 milhões de cabeças (USDA, 2017; ABIEC, 2020; ABIEC, 2021).

No Brasil, esse setor ganhou evidência no sistema do agronegócio e ocupou uma grande área do território nacional, no qual levou a um índice importante na criação de emprego e renda para a população brasileira. Além de gerar uma receita de 42 bilhões de reais para os frigoríficos e agregar um valor de 16,5 bilhões em impostos (Malafaia, et al., 2019). No Gráfico 1. observa-se a evolução do rebanho bovino no Brasil do ano de 1997 a 2020. 
Gráfico 1. Progresso do rebanho em número de bovinos no Brasil do ano de 1997 a 2020.

\section{Série histórica brasileira \\ Rebanho nacional}

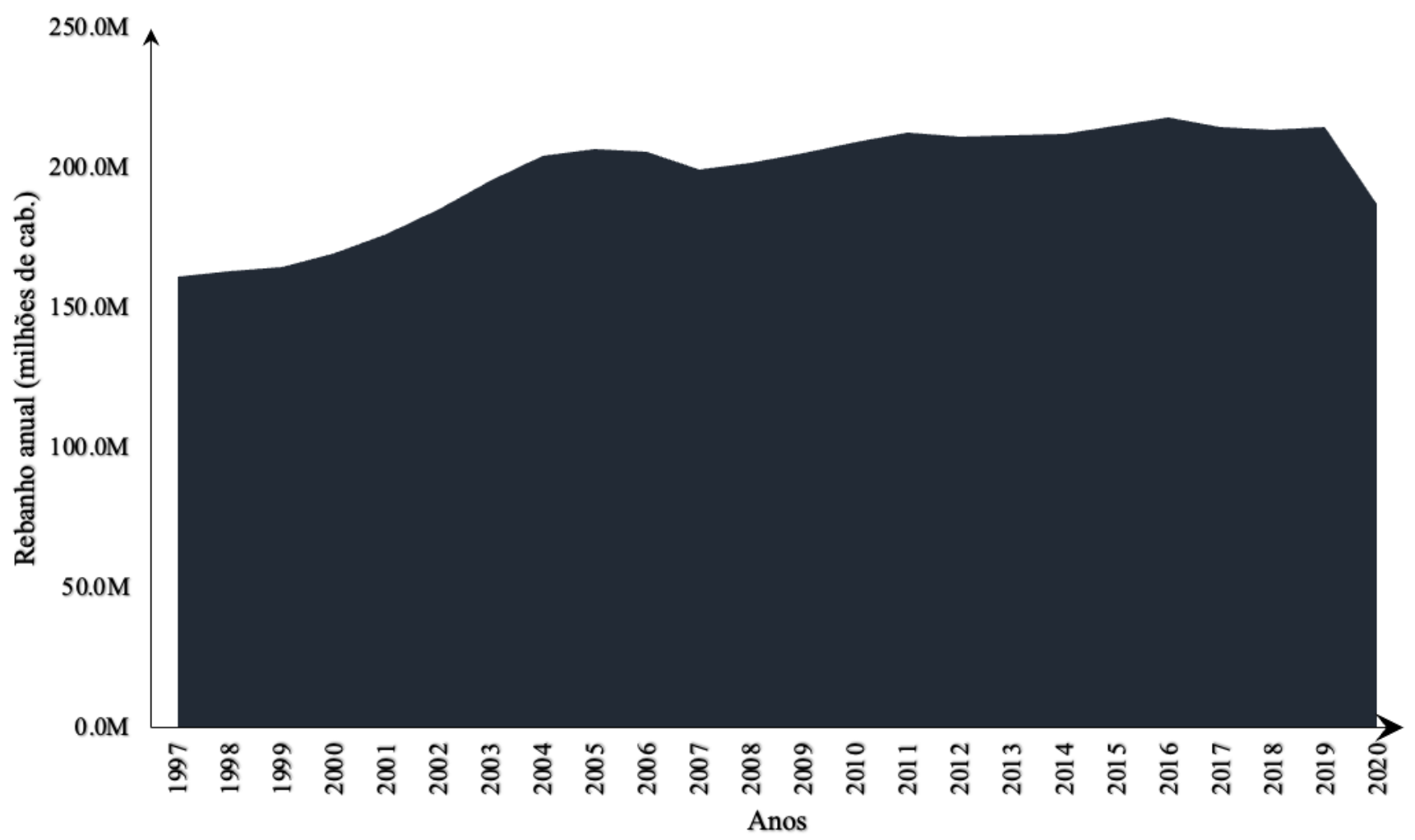

Fonte: Adaptado SIDRA/IBGE - Pesquisa da Pecuária Municipal.

O cenário atual do mercado da carne bovina no Brasil é bastante diferente do que se via há décadas atrás. Há cerca de 40 anos, havia menos da metade do rebanho atual, que praticamente não atendia nem o mercado interno. Além do aumento no rebanho, observou-se nessas quatro décadas, avanço nas áreas de pastagens, bem como aumento na produtividade. Tais evoluções levaram ao aumento do ganho de peso dos animais, diminuição na mortalidade e aumento na natalidade, bem como redução na idade ao abate. Isso foi possível devido a implantação de tecnologias nos eixos da alimentação, genética, manejo e saúde animal (Gomes, et al., 2017).

No objetivo de melhora na alimentação e manejo temos a intensificação dos sistemas de produção, como a terminação em confinamentos, observado no Gráfico 2., destacou o histórico do mesmo crescente e o abate estabilizado, denotando que no Brasil a cada ano é observado expansão da técnica.

O cenário atual do mercado da carne bovina no Brasil é bastante diferente do que se via há décadas atrás. Há cerca de 40 anos, havia menos da metade do rebanho atual, que praticamente não atendia nem o mercado interno. Além do aumento no rebanho, observou-se nessas quatro décadas, avanço nas áreas de pastagens, bem como aumento na produtividade. Tais evoluções levaram ao aumento do ganho de peso dos animais, diminuição na mortalidade e aumento na natalidade, bem como redução na idade ao abate. Isso foi possível devido a implantação de tecnologias nos eixos da alimentação, genética, manejo e saúde animal (Gomes, et al., 2017).

No objetivo de melhora na alimentação e manejo temos a intensificação dos sistemas de produção, como a terminação em confinamentos, observado no Gráfico 2., destacou o histórico do mesmo crescente e o abate estabilizado, denotando que no 
Brasil a cada ano é observado expansão da técnica.

Gráfico 2. Confinamento e abate de bovinos no Brasil a partir de 2001 até 2019.

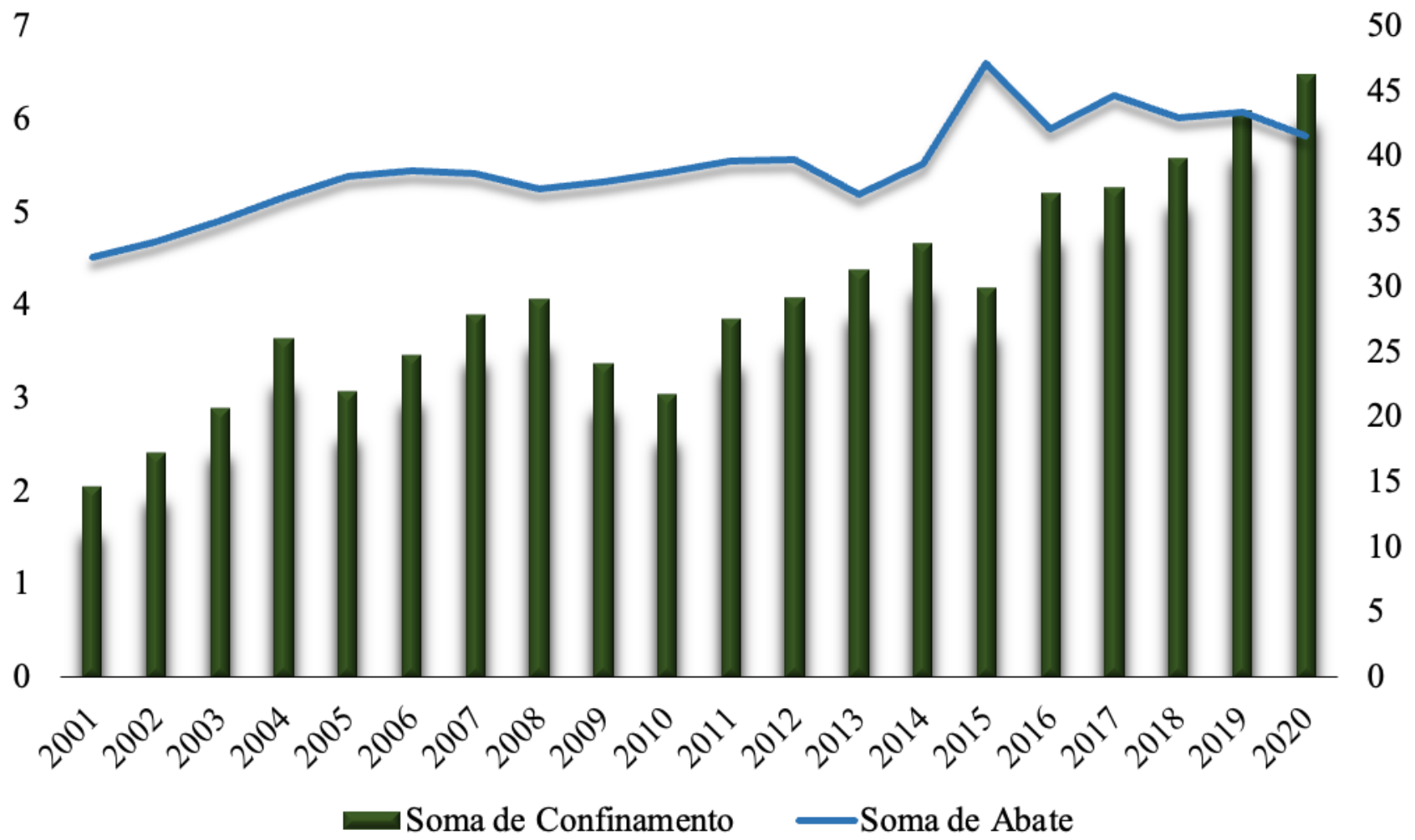

Fonte: Adaptado ABIEC (20200.

Estas implementações de tecnologias, teve como finalidade a produção de animais de ciclo curto com um melhor grau de acabamento de carcaça, fez com que esses animais fossem abatidos mais cedo. Tal fato gerou vantagens que tornam o sistema mais eficiente como: melhor qualidade de carne produzida, menor ciclo de produção, maior produção por área e giro de capital (Oliveira, 2021).

No ano de 2019, um novo cenário afetou seriamente a economia do Brasil, a pandemia do COVID-19. Apesar desse contexto, as exportações do agronegócio no país não sofreram impactos negativos. Observou-se em 2020 um aumento nas exportações de carne bovina, em que o maior percentual do exportado é de carne in natura. Além disso, foi registrado um aumento no número de países importadores da carne brasileira, registrado em cerca de 157 países.

As exportações de carne bovina in natura registraram recorde em valor (US \$7,45 bilhões) e quantidade (1,72 milhão de toneladas). A China foi o principal mercado de destino do produto, tendo adquirido 54,2\% (Figura 1.) do total exportado (US $\$ 4,04$ bilhões). 
Figura 1. Dez maiores compradores de carne bovina in natura brasileira, em porcentagem do volume embarcado, no primeiro semestre de 2021.

\section{Exportação de carne bovina In natura}

1 semestre 2021
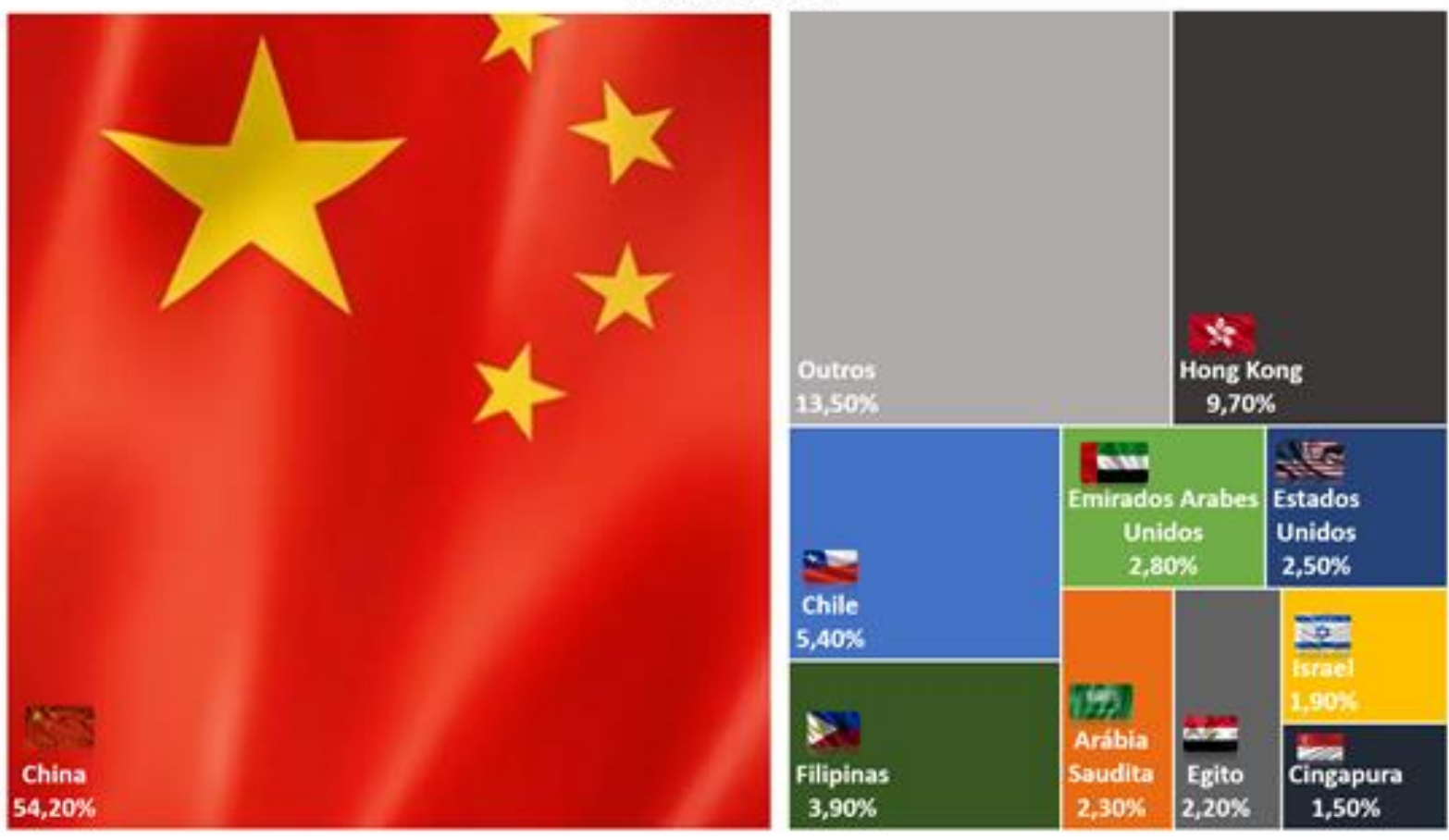

Fonte: Adaptado Scot consultoria.

Diante do crescimento positivo dentro dos parâmetros da pecuária brasileira, o resgate de bezerros pode ser uma estratégia para uma continua melhoria da eficiência da produção pecuária brasileira, de forma a intensificar o ciclo de produção, especificamente reduzindo o período de recria.

\section{Recria de bovinos}

Na pecuária brasileira é comumente dividida em sistemas em níveis tecnológicos e do grau de investimento adotados nas propriedades. Basicamente, o intensivo é o sistema de maior grau de todos os recursos tecnológicos disponíveis, o semiintensivo é o sistema de adoção de algumas técnicas, já o extensivo é caracterizado por um sistema que utiliza de grandes áreas, e baixos níveis de utilização de tecnologia.

No Brasil, o sistema de produção de carne bovina predomina a pecuária extensiva que depende basicamente das pastagens, restringindo a suplementação alimentar ao uso de sais minerais. Nesse cenário, não há investimento substancial, no qual outro fator a ser considerado, é época da seca do ano, os animais não conseguem obter resultados positivos com ganhos de peso, ou até mesmo a sua própria manutenção de desempenho corporal.

Atualmente, a criação de bovinos de corte é de suma importância econômica, no qual a atividade é de destaque no setor do agronegócio brasileiro. Apresentando como ponto forte, a produção com regime nutricional com uso de pastagens, entretanto, se faz necessário que ocorra melhorias quantitativa e qualitativa nestas áreas de pastagens para os índices de produtividade animal nestes sistemas sejam rentáveis (Sá de Sousa, et al., 2018).

Fatores que influenciam na bovinocultura de corte, estão correlacionados ao tipo de animal, o propósito da criação, a raça ou grupamento genético e a eco região onde a atividade é desenvolvida por uma propriedade.

O ciclo da produção de bovinos de corte do Brasil (Figura 2.), quando denominado de ciclo completo em que engloba 
todas as etapas (cria, recria e terminação). No qual a fase de cria é compreendida pela dependência do bezerro a sua progenitora, a etapa subsequente é compreendida no desempenho individual pós desmame, que do seu crescimento a composição em sua maioria é por hipertrofia de fibras muscular e nos últimos meses pré abate, designado como terminação, o crescimento ponderal tem como principal fonte o tecido adiposo (Barcellos, et al., 2020)

Figura 2. Fluxograma do ciclo completo da produção de bovinos de corte.

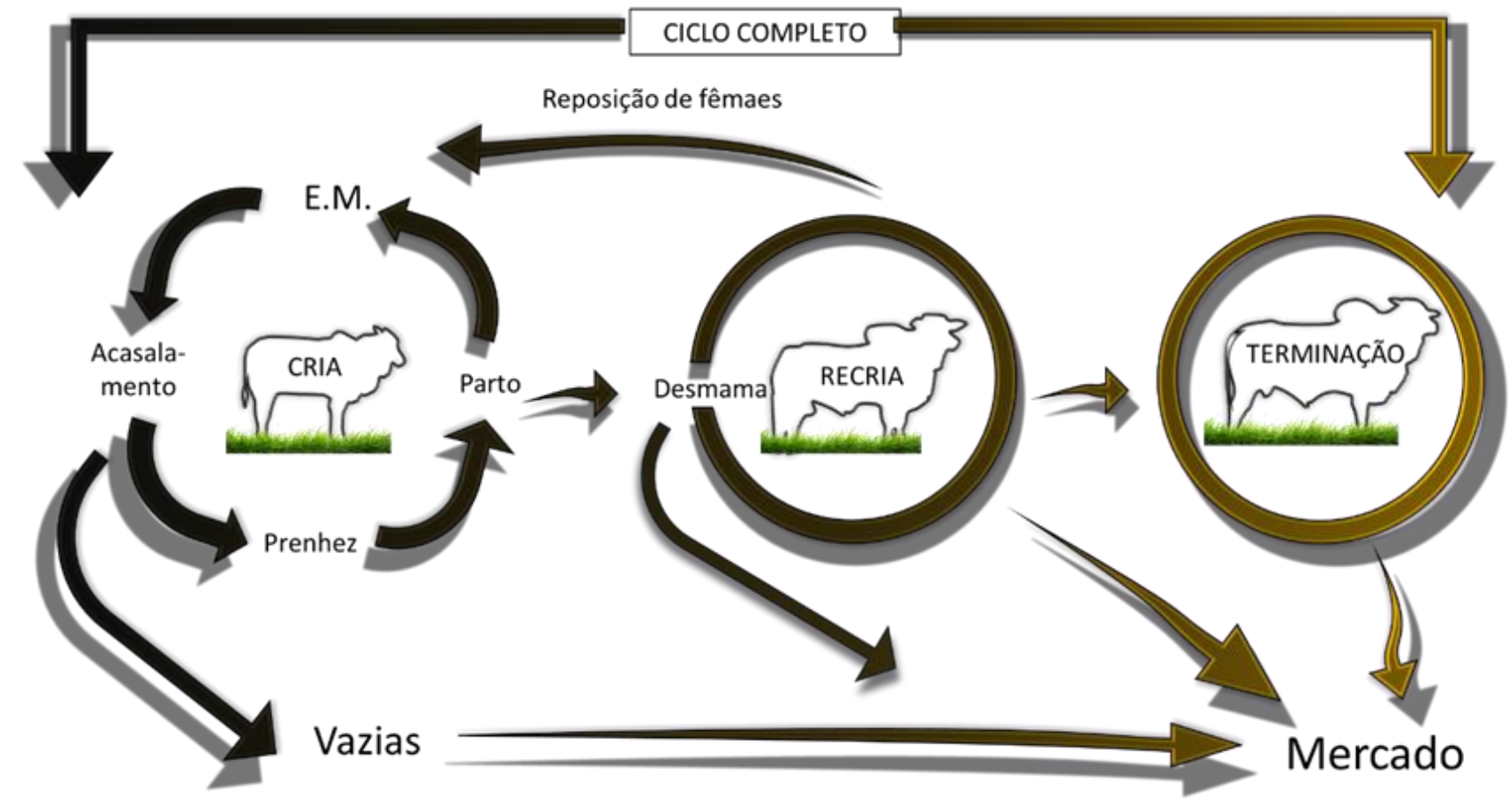

Fonte: Adaptado Lemos, et al. (2018).

Em propriedades em que a atividade específica é a fase de cria, isto é, propriedades comercializadoras de bezerros, as quais se tornam independentes das demais etapas, no qual as etapas posteriores, recria e engorda são altamente dependentes do produto da cria.

Na pecuária de corte, a cria é uma atividade vista de forma isolada, sendo compreendida como um sistema próprio de produção. Em qualquer uma das três situações a cria apresenta o mesmo fluxograma, entretanto, os bezerros podem seguir para propriedades com sistemas diferente, como a recria para posterior comercialização destes animais para propriedades especializadas em engorda (confinamentos), assim como outra situação em que as propriedades façam a recria e engorda.

Nos sistemas de cria, em que os animais saem direto para comercialização, os riscos eminentes da atividade, torna este sistema de produção onde qualquer erro irá impactar diretamente na rentabilidade do sistema, pois quando falamos em recria, a métrica a ser considerada é o número de bezerros desmamados por fêmea ano.

Os sistemas tradicionalistas de produção, que tendem a apresentar baixa produtividade, geram índices econômicos, comprometendo a viabilidade da propriedade em aderir tecnologias de manejo necessárias para melhorias em seus níveis de eficiência.

Já a recria de bovinos é o período compreendido entre a desmama, até a fase em que o animal entra no processo de terminação, o que leva aproximadamente 24 meses e chegam em média a 370kg (Pinto \& Millen 2018), representando a maior parte do ciclo de produção (Nascimento, 2021).

Ao final do período da seca, se coincidem com a época de parição e o desmame ocorre geralmente na passagem da 
água para seca, no qual compreende a fase de cria, que vai até os sete ou nove meses de idade, esse período é justamente quando os bezerros podem ser comercializados.

Na pecuária brasileira, há uma busca por aumento da produtividade associada a otimização de resultados econômicos. Devido às imposições da pecuária, o país contém em suas pastagens elementos fundamentais para o animal de corte, isso gera a redução dos custos da produção da carne (Oliveira, 2019).

\section{Estratégias nutricionais em períodos sazonalidades}

O país sofre com longos períodos de seca, o que torna um grande desafio manter uma nutrição adequada a bovinos, pois essa mudança climática faz com que as pastagens tenham um déficit qualitativo e quantitativo, isto é queda no seu valor nutricional, bem como redução seu crescimento, o que gera baixa oferta de forragens. Assim, o aumento consumo de alimento que o bovino deveria ingerir para atender sua demanda nutricional será maior, consequentemente o ganho de peso será inferior ao estimado (Lima, 2019).

Diariamente os bovinos precisam de água, energia, proteína, minerais e vitaminas, além das fibras dentro de parâmetros específicos, que ajudam no bom funcionamento do trato gastrointestinal. Dessa forma, se houver falta de algum desses elementos, as demandas nutricionais do animal devem ser conhecidas, para que seja feita a suplementação necessária, impedindo que ocorra a redução no ganho de peso do bovino, o que geraria aumento no tempo para alcance de peso ideal para o abate (Lima, 2019).

Diante desse cenário, o conhecimento zootécnico visa corrigir as deficiências quantitativas, de forma o uso de diferimento e manejo de pastagem, assim como qualitativo corrigidos a partir de suplementação de diversas naturezas (proteico, enérgico, proteico energético, sal mineral, etc.).

O uso de suplementação é de suma importância durante a época de seca do ano (inverno), período em que qualidade e disponibilidade da forragem tendem a diminuir consideravelmente, ocasionando em baixos teores de proteína e alta lignificação da fração fibrosa insolúvel (Paulino et al., 2008). Segundo Detmann et al. (2009), os teores de proteína bruta disponível (a partir de 7\%,), limita o crescimento microbiano, sobre os carboidratos fibrosos, resultando uma baixa utilização da parede celular potencialmente degradável pelos microrganismos ruminais e com isto desencadeando no comprometendo direto no consumo da pastagem e o desempenho animal (Egan \& Doyle, 1985; Leng, 1990; Paulino et al., 2008). Desta forma, a suplementação com compostos nitrogenados pode ser utilizada de forma estratégica a ser incluída a forragens de baixa qualidade por animais em regime alimentar a pasto (Leng, 1990; Sá de Souza, et al., 2018).

Quando em períodos de baixa disponibilidade de forragem e os animais não são suplementados, os desempenhos ficam abaixo do satisfatório, ao fim do período tendem a tornar-se inferior do estimado. Ao realizar a suplementação dos animais que estejam em déficit da exigência mínima nutricional no período de seca, no qual há um aumento da digestibilidade dos alimentos ingeridos. A adesão desta prática, tem por finalidade a correção da deficiência nutricional, propiciando ganho de peso ou manter seu peso corporal, com objetivo de não gerar comprometimento da eficiência econômica e produtiva da propriedade.

Dentro do regime alimentar a pasto de bovinos existem diversos fatores, no qual estão correlacionados, podendo serem enumerados como planta, o manejador do sistema, clima, solo, animal, entre outros. destes acima existem interaçõesespecíficas que visam a correção de forma integrada. No caso de bovinos em pastejo em ciclos longos podendo estarem em cima da área em período de um ano ou superior, no qual ocorre durante na época de sazonalidade forrageira contrastando todos os parâmetros produtivos, os mesmos são denominados de águas, seca e suas transições (Lima, 2019).

Assim, algumas estratégias são utilizadas para que esse problema possa ser reduzido. Uma delas é o processo de ensilagem, que consiste na conservação de forragem, com a finalidade de manter o valor nutricional da mesma parecido com o 
original, com o menor índice de perdas. Nesse método, carboidratos solúveis são convertidos em ácidos orgânicos através da proliferação de microrganismos que geram condições favoráveis à estabilidade anaeróbia, causando a conservação da forragem, sendo importante como reserva para os períodos de seca (Cândido, 2020).

O armazenamento da forragem sob forma de ensilagem encontrada em abundância no período chuvoso, tem como objetivo a utilização posterior do produto conservado. Isso faz com que consequentemente ela possa ser utilizada no período de estiagem, já que nesta época temos a escassez da oferta de forragem (Silva, et al., 2020).

Outra técnica de conservação de espécies forrageiras por longos períodos, é denominada de fenação. O objetivo deste processo, é promover a perda rápida de água pela planta forrageira com finalidade de evitar o mínimo de perdas nutricionais, físicas e químicas ao longo de todo o processo de fenação e armazenamento.

O processo fenação é uma estratégia utilizada, ao qual busca pela desidratação gradativa, seja estes por processos naturais ou artificiais, de plantas forrageiras com objetivos de obter menores perdas de seus valores nutritivos, conservando com isto, suas características de seu material verde (Andrade, 1999). A fenação consiste em um conjunto de várias operações mecânicas, que incluem o corte, condicionamento, enleiramento e enfardamento, para que posteriormente, o feno possa ser armazenado, se mantendo estável quando o teor de umidade é baixo (Silva et al., 2013), no qual é de extrema importância compreender que o ponto ideal de fenação para a finalidade de garantir que o produto mantenha os teores ideias de matéria seca, favorecendo a qualidade e diminuição das perdas no campo.

Dentre as estratégias, ainda podemos citar a técnica de diferimento, que consiste em selecionar uma área da pastagem e deixar de usá-la durante o período de chuva. Isso faz com que a forragem que irá se acumular nesse período seja usada na estação de seca. Essa estratégia chama atenção devido a praticidade e também o baixo custo (Santos, 2018).

Com objetivo de preservar a oferta de forragem aos animais no período seco, muitas propriedades utilizam de maneira estratégica a vedação de piquetes, ou seja, restringindo acesso de todo e qualquer animal ao consumo da forragem desta área. Esta prática de manejo faz com que alterações estruturais e morfológicas na composição do capim, que posteriormente será disponibilizado aos animais.

No momento em que os animais iram iniciar o pastejo nestas áreas diferidas, estes tendem a aumentar a taxa de bocado, ocasionando uma menor ingestão ao longo do dia (Santos 2017). Além do mais, o material consumido apresentará teores consumida apresentar teores de minerais, proteína bruta e energia, abaixo dos ideais, porém maior teor de fibra.

Outro manejo importante usado para elevar a produtividade e otimizar o desempenho econômico da atividade pecuária, é a utilização de adubos nitrogenados, que causam efeitos positivos na forragem, tanto na sua produção, como no seu valor nutricional. Tendo em vista que o nitrogênio é um dos nutrientes importantes que modulam os processos de desenvolvimento da forragem (Santos, 2020).

Com intuito de minimizar problemas de manejos alimentares, em épocas de escassez de forragem devem ser feitos ajustes de ganhos diários estimados com dietas com maiores teores de proteína bruta e energia (Razazzi, 2017). Algumas propriedades, com intuito de diminuir impactos de redução de custo, aderem como a estratégia de comercialização do boi magro na entressafra, para que o comprador realize a venda em períodos de escassez de animais acabados (Bitello, 2017).

\section{Confinamento e semiconfinamento como estratégia de recria de bovinos}

O confinamento é uma prática de manejo comumente utilizada na terminação de animais, entretanto, ao longo dos anos pode-se também ser uma estratégia para recria de animais, buscando a intensificação de ganhos e encurtamento do período. A prática em si, consiste na separação dos animais em lotes com área delimitada em metros quadrados dimensionados por animal, e o fornecimento da alimentação determinada em cochos e bebedouros d'água com fornecimento ad libitum (Medeiros, et al., 2015). 
O sistema do semiconfinamento permite que o produtor utilize além dos pastos naturais, um complemento alimentar para o rebanho, a suplementação geralmente varia de acordo com a região e vem trazendo resultados positivos para os produtores de bovinos de corte, principalmente no Brasil que dispõe de condições favoráveis para a criação (Siqueira, 2018).

Na literatura, o dimensionamento do confinamento como um todo, para o tamanho das baias é sugerido cerca de 10 $\mathrm{m}^{2}$ por animal, com área de cochos considerando respectivamente, $0,70 \mathrm{~m}^{2}$ a $0,55 \mathrm{~m}^{2}$ lineares por animal. Os bebedouros são dimensionados a fim de atender o consumo de água pelos animais, cerca de 8 a $10 \%$ em relação ao seu peso vivo, preconizando o bem estar dos animais, se atentando ao número de animais em função do tamanho corporal dos mesmos, quanto mais heterogêneo o lote, difícil será o manejo (Guimarães, et al., 2017; Dias Filho, 2011).

A homogeneidade de lotes, se deve pelo fato de a dieta ser totalmente calculada em cima do percentual de ingestão de matéria seca com base no peso corporal inicial, idade fisiológica, sexo, padrão racial e grau de acabamento, no qual é estimado um ganho médio diário a ser alçando alterando a percentagem de ingestão de matéria de seca, para cada objetivo fixado. O tempo de confinamento pode ser variado ou fixo, isto irá depender do objetivo, no qual o mesmo pode ser de 80 a 120 dias de duração (Oliveira e Millen, 2014).

Em ruminantes confinados, usualmente é utilizado um teor mínimo de cerca de $20 \%$ de fibra fisicamente efetiva, com a finalidade do bom funcionamento do ambiente ruminal com o estimulo da mastigação e produção de saliva, com proposito do tamponamento ruminal (NRC, 2001; Zebeli, et al., 2012), que normalmente apresenta na composição bromatológica das pastagens com finalidade do bom funcionamento ruminal, entretanto foi visto pelos autores que acima de $32 \%$ foi prejudicial ao consumo pelo fator físico. Está se atentando-se nas últimas décadas o uso de dietas de grão inteiro com suas particularidades (Sousa, et al., 2018)

Dentre as fontes de volumosos mais usuais nas dietas, a principal utilizada é a silagem, podendo ser de grãos (milho, capulho de algodão, milheto, sorgo, etc.) e gramíneas (Mombaça, Ruziziensis, Capim Elefante, etc.), coprodutos de indústrias (resíduo de milho de destilarias, bagaço de cana, polpa cítrica, briquete de algodão, etc.)

O regime de confinamento para a bovinocultura tornou uma ferramenta estratégica, desde que haja um planejamento anterior a sua implantação, dentre os principais, os custos de produção e compras, como a aquisição de animais e insumos referentes à alimentação, são os principais fatores a serem analisados para a viabilidade e rentabilidade do sistema (Silva, et al., 2018).

Nascimento (2021), avaliou 104 animais em confinamento para a fase terminação por 141 dias, do dia 1 ao 16 , os animais consumiram uma dieta para adaptação, entre os dias 17 e 21 foi oferecida uma dieta de adaptação e crescimento, dos dias 22 a 51 eles consumiram apenas alimentação para crescimento, entre os dias 52 e 56, novamente houve a mistura da dieta de crescimento e terminação, e a partir do 57 dia os animais consumiram apenas alimentação referente a fase de terminação, denotando que o intuito da fase de recria destes animais, não era a deposição de tecido adiposo antecipada, afim de comprometer o crescimento fisiológico regular.

O experimento teve duração de 375 dias, divididos em duas etapas (recria e terminação), utilizando o delineamento em fatorial com 2 fatores, em que o fator 1 foi o manejo na transição secas-águas (pasto vs. confinamento) e o fator 2 foi de estratégias nutricionais nas águas (suplemento mineral vs. suplemento proteico energético).

No primeiro tratamento foi fornecido á pasto suplemento proteico energético ( $5 \mathrm{~g} / \mathrm{kg}$ PC) do dia 1 a 63 e suplemento mineral (ad libitum) do dia 64 a 244, no segundo tratamento, foi fornecido a pasto suplemento proteico energético (5 g/kg PC) do dia 1 a 63 e suplemento proteico energético ( $3 \mathrm{~g} / \mathrm{kg}$ PC) do dia 64 a 244, em quanto no terceiro tratamento os animais foram alocados em confinamento (dieta a base de silagem de milho, milho moído, farelo de algodão e núcleo mineral (5 g/kg PC de concentrado) do dia 1 a 63 e em pastagem recebendo suplemento mineral (ad libitum) do dia 64 a 244, no quarto tratamento, os bezerros foram alocados em confinamento (dieta a base de silagem de milho, milho moído, farelo de algodão e núcleo mineral 
( $5 \mathrm{~g} / \mathrm{kg}$ PC de concentrado) do dia 1 a 63 e em pastagem recebendo suplemento proteico energético (3 g/kg PC) do dia 64 a 244.

Na transição secas-águas foram formuladas dietas com ganho estimado de $0,800 \mathrm{~kg} / \mathrm{dia}$, já para a época das águas, foram estimados ganhos de $0,700 \mathrm{~kg} / \mathrm{dia}$ e para terminação, ganho de 1,500 kg/dia, todas as dietas foram formuladas em cima do BR-CORTE (2010).

Em 68 animais da raça Nelore submetidos no regime de semiconfinamento por 129 dias, Bento et al. (2019) avaliaram o desempenho dos animais durante o período, todos receberam diariamente uma alimentação balanceada estimada para um ganho médio diário de $1,2 \mathrm{~kg}$, com suplementos protéicos-energéticos duas vezes ao dia, durante os 14 dias iniciais, a dieta foi direcionada a fase de adaptação. Ao final do experimento, os animais chegaram a ter um ganho médio diário de até $1,25 \mathrm{~kg}$ por dia, superando as expectativas iniciais. Esses dados corroboram com os disponíveis na literatura, onde a suplementação promove uma resposta linear crescente no ganho de peso dos animais.

Existe também o confinamento uma alternativa de extrapolar o volume de consumo de matéria seca denominado de expresso. Nesta alternativa e os animais continuam na própria fazenda em pastagem vedada para a fase final de engorda, geralmente essas propriedades não contam com estruturas tradicionais de confinamentos, porém tem se mostrado promissora pelo baixo custo e eficiência. Esse sistema se difere dos demais pela \% de MS por peso vivo (cerca de $2 \%$ ) oferecida e a formulação da dieta (dispõe de um núcleo proteico, onde é inserido fontes energéticas), além de oferecer ganho significativo de peso, não gera distúrbios metabólicos ao animal (Siqueira., 2018).

Considerando bons índices na fase final dos animais, os desempenhos anteriores criam e recriam) têm papéis fundamentais, pois a curva de crescimento dos animais não se estabiliza ou entra em declínio podendo ocorrer uma ruptura de ganho assim prejudicando o sistema como todo (Oliveira, 2019; Pinto e Millen, 2018).

\section{Recria intensiva de bovinos em confinamento}

Nos EUA a prática é vista incluindo muitos animais cruzados no qual $40 \%$ dos bezerros desmamados (Greenwood, 2021) denominados de "Calf-fed" e colocados em confinamentos por 240 dias, em que é discutido no estudo que devem conter um alto teor de concentrado e deve se evitar a alta deposição de gordura antes da entrada no confinamento.

Em muitos países esta estratégia é utilizada em recria de bovinos leiteiros, muitas vezes utilizando principalmente dietas com produtos de ingredientes oriundos do milho não direcionados para a deposição de gordura corporal, e sim de crescimento muscular corporal encontrando em novilhas Holandesas no final do ciclo de 112 dias de confinamento com ganhos médios de 1,30 kg/dia, terminando o período com $276 \mathrm{~kg}$ de peso corporal final (Buenabad et al., 2020).

Em uma amostragem histórica de 1981 a 2011 (Legesse et al., 2016), para produção de bovino no Canadá, avaliaram três sistemas de terminação. No qual foram designados como, sistema 1 (bezerros desmamados inseridos diretamente no confinamento), sistema 2 (os animais entram no regime de crescimento de 8 aos 18 meses, posteriormente terminados em confinamento) e sistema 3 (desmamados aos 8 meses inseridos diretamente no confinamento, posterior retorno a pasto e finalizados em confinamento).

De acordo com os resultados de Legesse et al., (2016), a longo dos anos em todos os três sistemas o peso dos animais, eram de 524,3 kg para 593,3 kg, e o ganho médio diário era de 1,08 kg para 1,28 kg, e ocorreu uma redução na idade ao abate dos animais (Figura 3.). 
Figura 3. Linha do tempo do nascimento ao abate de bovinos de corte, produzidos no Canadá em 2011.

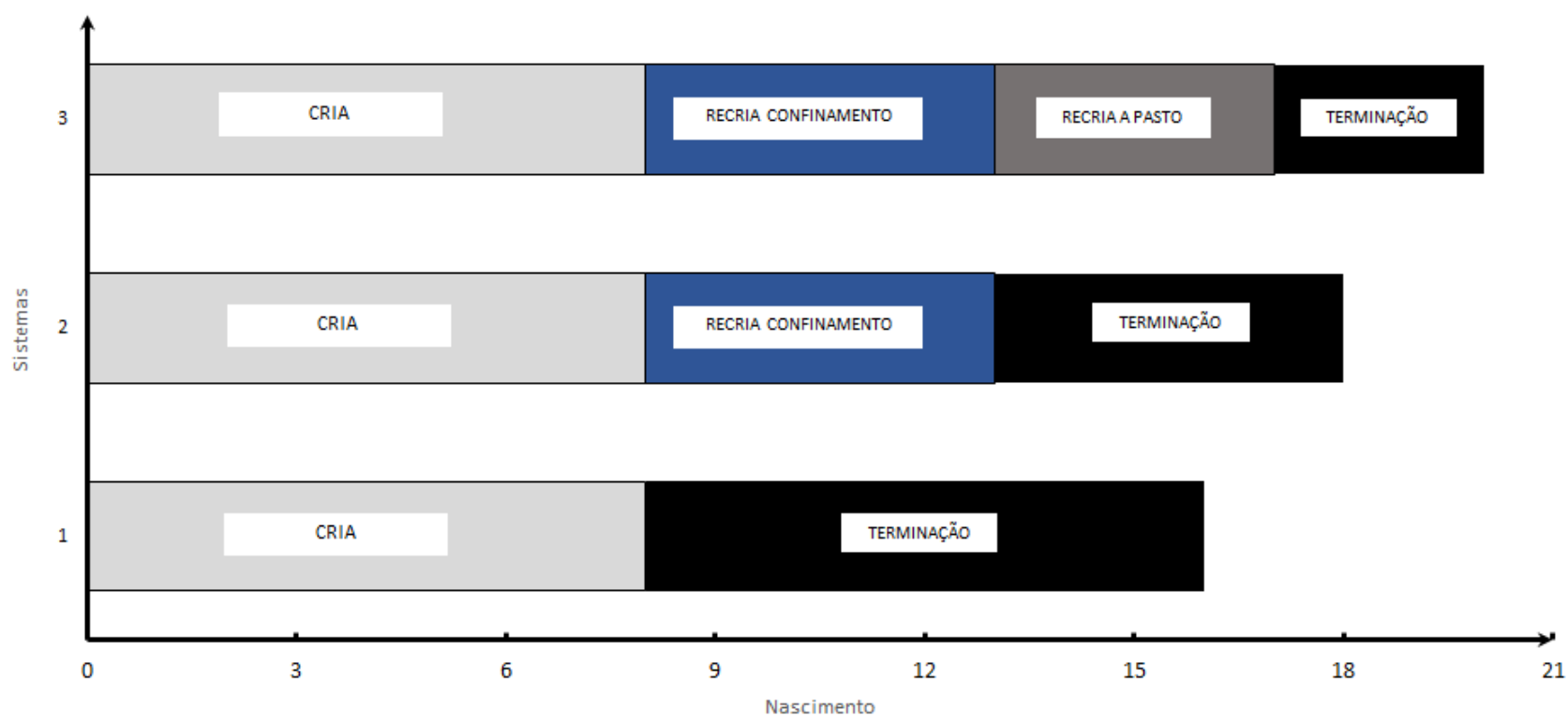

Fonte: Adaptado Legesse et al. (2016)

Entre outros índices zootécnicos (Tabela 1.) para os mesmos autores evidenciaram que independe do sistema, como a métrica de ganho médio diário foi otimizado ao longo do tempo. Em 2011 comparando dentre os sistemas suas magnitudes foram semelhantes para ambos, elucidando o custo do animal produzido.

Comparando entre sexos, é esperado a diferenciação de desempenho, entretanto, as novilhas ainda em 2011 apresentaram resultados satisfatórios, pois é visto no gráfico que o ganho obtido é oriundo de animais de recria, com foco no sistema no qual os animais foram recriados em parte em confinamento e o restante a pasto.

Tabela 1. Tipos de sistemas de produção de bovinos de corte no Canadá de 1981 a 2011.

\begin{tabular}{|c|c|c|c|c|}
\hline Sistemas & Parâmetro & Crescimento a confinamento & Crescimento a pasto & Terminação \\
\hline \multicolumn{5}{|c|}{ 1981-Novilho } \\
\hline \multirow{4}{*}{$1^{\mathrm{A}}$} & Peso inicial $(\mathrm{Kg})$ & - & - & 249 \\
\hline & Peso final $(\mathrm{Kg})$ & - & - & 499 \\
\hline & Duração(dias) & - & - & 240 \\
\hline & Ganho diário (kg/dia) & - & - & 1.04 \\
\hline \multirow{4}{*}{$2^{\mathrm{B}}$} & Peso inicial $(\mathrm{Kg})$ & 226 & - & 370 \\
\hline & Peso final (Kg) & 370 & - & 533 \\
\hline & Duração(dias) & 180 & - & 150 \\
\hline & Ganho diário (kg/dia) & 0.80 & - & 1.09 \\
\hline \multirow{4}{*}{$3^{\mathrm{C}}$} & Peso inicial $(\mathrm{Kg})$ & 203 & 327 & 431 \\
\hline & Peso final $(\mathrm{Kg})$ & 327 & 431 & 541 \\
\hline & Duração(dias) & 180 & 150 & 100 \\
\hline & Ganho diário (kg/dia) & 0.69 & 0.70 & 1.10 \\
\hline \multicolumn{5}{|c|}{ 1981-Novilha } \\
\hline 1 & Peso inicial $(\mathrm{Kg})$ & - & - & 234 \\
\hline
\end{tabular}


Research, Society and Development, v. 11, n. 2, e1611225179, 2022

(CC BY 4.0) | ISSN 2525-3409 | DOI: http://dx.doi.org/10.33448/rsd-v11i2.25179

\begin{tabular}{|c|c|c|c|c|}
\hline & Peso final $(\mathrm{Kg})$ & - & - & 393 \\
\hline & Duração(dias) & - & - & 240 \\
\hline & Ganho diário (kg/dia) & - & - & 0.67 \\
\hline \multirow{4}{*}{2} & Peso inicial (Kg) & 212 & - & 322 \\
\hline & Peso final $(\mathrm{Kg})$ & 322 & - & 426 \\
\hline & Duração(dias) & 180 & - & 150 \\
\hline & Ganho diário (kg/dia) & 0.61 & - & 0.69 \\
\hline \multirow{4}{*}{3} & Peso inicial (Kg) & 191 & 283 & 361 \\
\hline & Peso final $(\mathrm{Kg})$ & 283 & 361 & 433 \\
\hline & Duração(dias) & 180 & 150 & 110 \\
\hline & Ganho diário (kg/dia) & 0.51 & 0.51 & 0.66 \\
\hline \multicolumn{5}{|c|}{ 2011-Novilho } \\
\hline \multirow{4}{*}{1} & Peso inicial $(\mathrm{Kg})$ & - & - & 299 \\
\hline & Peso final (Kg) & - & - & 623 \\
\hline & Duração(dias) & - & - & 240 \\
\hline & Ganho diário (kg/dia) & - & - & 1.35 \\
\hline \multirow{4}{*}{2} & Peso inicial (Kg) & 271 & - & 454 \\
\hline & Peso final $(\mathrm{Kg})$ & 454 & - & 666 \\
\hline & Duração(dias) & 180 & - & 145 \\
\hline & Ganho diário (kg/dia) & 1.01 & - & 1.47 \\
\hline \multirow{4}{*}{3} & Peso inicial $(\mathrm{Kg})$ & 243 & 390 & 508 \\
\hline & Peso final $(\mathrm{Kg})$ & 390 & 508 & 676 \\
\hline & Duração(dias) & 180 & 120 & 100 \\
\hline & Ganho diário (kg/dia) & 0.82 & 0.98 & 1.68 \\
\hline \multicolumn{5}{|c|}{ 2011-Novilha } \\
\hline \multirow{4}{*}{1} & Peso inicial $(\mathrm{Kg})$ & - & - & 281 \\
\hline & Peso final $(\mathrm{Kg})$ & - & - & 562 \\
\hline & Duração(dias) & - & - & 240 \\
\hline & Ganho diário (kg/dia) & - & - & 1.17 \\
\hline \multirow{4}{*}{2} & Peso inicial (Kg) & 255 & - & 408 \\
\hline & Peso final $(\mathrm{Kg})$ & 408 & - & 609 \\
\hline & Duração(dias) & 180 & - & 160 \\
\hline & Ganho diário (kg/dia) & 0.85 & - & 1.25 \\
\hline \multirow{4}{*}{3} & Peso inicial $(\mathrm{Kg})$ & 229 & 361 & 462 \\
\hline & Peso final $(\mathrm{Kg})$ & 361 & 462 & 619 \\
\hline & Duração(dias) & 180 & 120 & 110 \\
\hline & Ganho diário (kg/dia) & 0.73 & 0.84 & 1.43 \\
\hline
\end{tabular}

$\mathrm{A}=$ Sistema 1- Animais desmamados inseridos diretamente no confinamento; $\mathrm{B}=-$-Sistema 2 Animais entram no regime de crescimento de 8 aos 18 meses, posteriormente terminados em confinamento; $\mathrm{C}=$ Sistema 3 Animais desmamados aos 8 meses inseridos diretamente no confinamento, posterior retorno a pasto e finalizados em confinamento). Fonte: Adaptado Legesse et al. (2016)

Para Klopfenstein et al. (2000), sistemas intensificados de recria intensiva de bezerros confinados, houve diferença significativa no peso final de animais confinados após 12 meses de idade. Porém, a estratégia depositou na carcaça uma diferença de $0,25 \mathrm{~cm}$ de gordura, com ganho diário de $1,26 \mathrm{~kg}$.

Salinas-Chavira et al., (2016), usando aditivos contendo virginiamicina e dietas suplementadas com aminoácidos metabolizáveis atendendo as exigências nutricionais. Durante os 112 dias iniciais de alimentação, foram utilizados bezerros 
com peso inicial de média $127 \mathrm{~kg}$ em um período de 196 dias, com peso final de 575,25 kg com ganhos diários de até 1,67 kg. Diante os resultados, a estratégia não tem como premissa ganhos elevados, e sim, um crescimento contínuo dos animais, para fim de evitar a deposição de tecido adiposo precoce.

Em parâmetros qualitativos de contra filés de animais, (Roy et al., 2021) avaliando vários critérios da carne, principalmente o teor de colágeno intramuscular, foram três tipos de tratamentos confinados no período do desmame, a partir de 20 meses e animais adultos mestiços, em que o acúmulo deste tecido pode estar relacionado ao endurecimento da carne. Neste estudo foi confirmado que ao longo da vida do animal a tendência foi aumento de colágeno.

Barbero et al. (2017), avaliaram em seu estudo a importância do conhecimento dos produtores sobre a fase de recria, pois é nela que o animal deve adquirir peso significativo em relação às demais, por isso, atualmente há uma procura por um sistema de produção mais eficiente com objetivo de atender em um período de até 12 meses perante as demandas nutricionais na recria. Isso leva aos animais iniciarem a fase de terminação com peso mais elevado, gerando abates de animais precoces e com melhor qualidade da carne.

Estratégias de intensificação são utilizadas para diminuir o período da fase de recria, dentre elas incluem a suplementação concentrada no decorrer do período de seca e a recria em confinamento. Tudo isso tem sido utilizado com o objetivo de aumentar a oferta de nutrientes desse período, logo os animais permanecem em confinamento até que o produtor detenha novamente disponível um pasto de qualidade e com condições para que o animal não perca peso (Pais, et al., 2019; Souza, 2018).

Segundo Nascimento (2021), o Brasil tem utilizado a técnica de confinamento dos bezerros após a desmama como estratégia para produção do gado de corte, trata-se de uma opção segura e viável para os produtores rurais, permitindo a criação de animais com grande potencial produtivo. Para o manejo dos bezerros, é essencial que todo o processo seja conhecido, com o intuito de prosseguir com os ganhos de peso ao rebanho, bem como a venda e comercialização da carne (Valle e Pereira, 2019).

Roth et al., (2019), evidenciaram o uso de suplementação dos bovinos de corte de 16 meses de idade, a intensificação ajuda a potencializar o aumento do peso do animal, bem como melhora o rendimento da carcaça e da carne, também tem como benefício o encurtamento do ciclo de vida. Todas as estratégias utilizadas durante a recriam afetam diretamente o desempenho futuro dos animais e aqueles que durante essa fase obtiverem variáveis diferentes, iniciam a fase terminação também com índices corporais diferentes, isso gera carcaças de pesos desuniformes, consequentemente, acarretando resultar em variação na remuneração final pela falta de padronização do produto final (Costa, et al., 2018).

Para que a terminação ocorra de maneira mais rápida ao longo de todo o processo, tem se utilizado a intensificação de bezerros em confinamento, devido esta categoria na recria não ser suplementada e pelo menos monitorada ao momento adaptação do desmame. Assim como, ao passarem por períodos de transição, especificamente períodos chuvosos para a seca, além de oferecer um pasto de menor qualidade em nutrientes, e quantidade suficiente para os bezerros, fazendo com que haja perdas de peso e queda no ganho e aumento no período do processo de recria seja necessário (Valle e Pereira, 2019).

Esse método tem como principal objetivo fornecer ao animal os nutrientes essenciais para o bom desenvolvimento nas diferentes estações do ano, otimizando ganhos e sem que haja perda de peso. Essa prática de manejo durante o período de seca pode resolver dois possíveis problemas simultaneamente: melhor condição para o retorno do pasto e intensificação na recria, reduzindo o período ao abate (Barroso, 2018).

Por tanto, o sequestro de bezerros pode aumentar consideravelmente a taxa anual de abate, devido à maturidade sexual antecipada das novilhas, aumentando a rentabilidade e competitividade dos produtores. Além de que, uma recria de curto período condiciona os animais para a terminação, não passando por duas secas consecutivas a pasto. Em épocas de seca os níveis proteicos diminuem consideravelmente, necessitando de uma suplementação nitrogenada, especialmente para os 
bezerros em crescimento. A recria desses animais deve ser visto como estratégia de melhoria no acabamento e qualidade das carcaças, o sistema tradicional de produção em pastos convencionais pode gerar atrasos, bem como postergar a idade de abate dos animais, e comprometimento de parâmetros econômicos (Oliveira, 2017).

A evolução da tecnologia é constante e sua aplicação tem se mostrado bastante favorável quando bem utilizada e na agropecuária não é diferente. O sistema tradicional de criação, chegava de quatro a cinco anos por ciclo de criação, no cenário atual é possível acelerar o processo em apenas dois anos para todo o ciclo, com um maior giro (Caetano et al., 2020) e sem prejuízos para a carcaça.

O manejo e reforma dos pastos, bem como o isolamento de bezerros das pastagens são uma forma de acelerar a produção dos animais, e a execução do manejo de recuperação de pastagens é realizada no mesmo período em que animais estão confinados.

Deve ser estudado o confinamento dos bezerros como estratégia vantajosa não só pelo fato do ganho de peso, mas pelo período edafoclimático a ser passado na transição de secas-águas, no qual o pasto pode se recuperar mais rapidamente pela baixa ou inexistente.

\section{Considerações Finais}

A intensificação da recria favorece a permanência da agroindústria no setor, com isso, fortalecendo o produtor na atividade ao longo prazo. Essa estratégia de produção favorece a competitividade do sistema, de forma que este planejamento faça um manejo otimizado e maior poder de comercialização em cenários de maior demanda de mercado consumidor e simultaneamente de escassez de animais prontos para o abate.

Com a adoção da recria intensiva, a estratégia de maior desempenho a qual os animais retornaram aos pastos, antes da terminação em confinamento, no momento do retorno do pastejo, atentando em fornecer níveis leveis de suplementação, com intuito de não ocorrer perdas do crescimento dos períodos antecedentes.

O principal objetivo do confinamento de animais em recria, é manter a curva de crescimento positiva, entretanto, com limite de ganho médio diário, pois a estratégia não será deposição de gordura neste período, no contrário o custo desta operação se tornará onerosa, até mesmo pelos custos dos insumos.

Para futuras investigações futuras é visto a viabilidade técnica sobre a temática, mas é preciso avaliar o impacto financeiro com o manejo adotado como um todo na propriedade para obter uma tomada de decisão mais robusta na intensificação do mesmo.

\section{Referências}

ABIEC. (2020). Associação Brasileira das Indústrias Exportadoras de carne. Perfil da Pecuária no Brasil, http://abiec.com.br/publicacoes/beef-report-2020/.

ABIEC. (2021). Associação Brasileira das Indústrias Exportadoras de carne. Perfil da Pecuária no Brasil, http://abiec.com.br/publicacoes/beef-report-2021/.

Andadre, J. B. (1999) Produção de Feno. 34p. Nova Odessa, Instituto de Zootecnia.

Barbero, R. P., Malheiros, E. B., Nave, R. L., Mulliniks, J. T., Delevatti, L. M., Koscheck, J. F. \& Reis, R. A. (2017). Influence of post-weaning management system during the finishing phase on grasslands or feedlot on aiming to improvement of the beef cattle production. Agricultural Systems, 153 , 23-3. https://doi.org/10.1016/j.agsy.2017.01.015.

Barcellos, J. O. J., Lima, J. A., de Oliveira, T. E., Zago, D., Fagundes, H. X. \& Lima, V. (2020). Bovinocultura de corte: cadeia produtiva \& sistemas de produção (3). Agrolivros.

Barroso, D. S. (2018). Recria e terminação de novilhos, sob diferentes níveis de suplementação em pastagens. Tese (Doutorado em Zootecnia) - Itapetinga, Bahia, Universidade Estadual do Sudoeste da Bahia.

Bento, F. C., Rovani, E. A., Mesquita, G. F., Ruiz, L. R. B., da SILVA, M. I. L., de Andrade Moreira, P. S. \& Gomes, H. F. B. (2019). Efeito dos níveis de suplementação no desempenho de bovinos em sistema de semi-confinamento. Nativa, 7(6), 813-819. http://dx.doi.org/10.31413/nativa.v7i6.7090. 
Bitello, M. F. D. O. (2017). Estratégia de venda de boi gordo em uma fazenda de bovinos de corte de ciclo completo. TCC (curso de agronomia ) Faculdade de Agronomia. Universidade Federal do Rio Grande do Sul.

Buenabad, L., Latack, BC \& Zinn, RA. (2019). Efeito dos níveis de cálcio suplementar no desempenho do crescimento em confinamento e na utilização da energia líquida da dieta durante o período de alimentação de novilhos holandeses alimentados com bezerros. Open Journal of Animal Sciences , 10 (1), 1-9. https://doi.org/10.4236/ojas.2020.101001.

Cândido, M. J. D. \& Furtado, R. N. (2020). Estoque de forragem para a seca: produção e utilização da silagem. - Disponível em: http://repositorio.ufc.br/bitstream/riufc/53687/1/2020_liv_mjdcandido.pdf. Acesso em: 28 de junho de 2021.

Costa, J. P. R., De Jesus, R. B., Oliveira, I. M., Resende, F. D., Siqueira, G. R. \& Malheiros, E. B. (2018). Does virginiamycin supplementation affect the metabolism and performance of Nellore bulls grazing under low and high gain rates? Animal Science Journal, 89(10), 1432-1441. DOI: 10.1111/asj.13052.

Delevatti, L. M., Romanzini, E. P., Koscheck, J. F. W., de Araujo, T. L. D. R., Renesto, D. M., Ferrari, A. C.\& Reis, R. A. (2019). Forage management intensification and supplementation strategy: Intake and metabolic parameters on beef cattle production. Animal Feed Science and Technology, $247,74-82$. ://doi.org/10.1016/j.anifeedsci.2018.11.004

Detmann, E., Paulino, M. F., Mantovani, H. C., Valadares Filho, S. D. C., Sampaio, C. B., de Souza, M. A. \& Detmann, K. S. (2009). Parameterization of ruminal fibre degradation in low-quality tropical forage using Michaelis-Menten kinetics. Livestock Science, 126(1-3), 136-146. https://doi.org/10.1016/j.livsci.2009.06.013

Dias Filho, A. (2011). Técnicas aplicadas para o confinamento de bovinos. (TCC). Curso de Medicina Veterinária 53p Universidade de Brasília.

Egan, J. K., \& Doyle, P. T. 1985. Effect of intraruminal infusion of urea on the response in voluntary food intake by sheep. Australian Journal of Agricultural Research, 36(3), 483-495. https://doi.org/10.1071/AR9850483

Gomes, R. C.; Feijó, G. L. D. \& Chiari, L. (2017). Evolução e Qualidade da Pecuária Brasileira. EMBRAPA - Empresa Brasileira de Pesquisa Agropecuária. Ministério da Agricultura, Pecuária de Abastecimento. Corte https://www.bibliotecaagptea.org.br/zootecnia/bovinocultura/livros/NOTA\%20TECNICA\%20EMBRAPA\%20GADO\%20DE\%20CORTE.pdf.

Greenwood, P. L. (2021). O jornal internacional de biociências animal. https://doi.org/10.1016/j.animal.2021.100295.

Guimarães, L. A., de Nardi Junior, G. \& Oliveira, P. A. (2017). Análise E Viabilidade Econômica Em Um Sistema De Confinamento Para A Terminação De Gado De Corte Anelorado. Tekhne e Logos, 8(1), 42-52.

Klopfenstein, TJ, Cooper, R., Jordon, DJ, Shain, D., Milton, T., Calkins, CR, \& Rossi, C. (1999). Efeitos de programas de cultivo em segundo plano e crescimento na qualidade e produtividade da carcaça bovina. J. Anim. Sci. 77(1)-11.

Legesse, G., Beauchemin, KA, Ominski, KH, McGeough, EJ, Kroebel, R., MacDonald, D., ... \& McAllister, TA (2015). Emissões de gases de efeito estufa da produção canadense de carne bovina em 1981 em comparação com 2011. Animal Production Science, 56 (3), 153-168. http://dx.doi.org/10.1071/AN15386

Lemos, R. A.S., Pegorini, M. A., da Motta, M. E. V., Camargo, M. E., Fernandes, A. M. 2018. Custo de oportunidade de recria e engorda de gado bovino de corte. v. 14, n. 3, (2018). http://www.custoseagronegocioonline.com.br/numero3v14/OK\%205\%20oportunidade.pdf.

Leng, R.A. (1990). Fatores que afetam a utilização de forragens de 'má qualidade' por ruminantes, particularmente em condições tropicais. Revisões de pesquisas sobre nutrição, $3(1), 277-303$.

Lima, V. R. A. (2019). Estratégias de suplementação de bovinos de corte criados a pasto no período de estacionalidade de produção de forragens. (TCC)Trabalho de Conclusão na área de Bovinocultura de Corte. Centro Universitário do Planalto Central Aparecido dos Santos, 2019.

Malafaia, G. C., Biscola, P. H. N.,\& Dias, F. R. T. (2020). Os impactos da COVID-19 para a cadeia produtiva da carne bovina brasileira. Embrapa: Comunicado Técnico, 154, 1-8.

Malafaia, G. C., de Azevedo, D. B., Pereira, M. D. A. \& MATIAS, M. D. A. (2019). A sustentabilidade na cadeia produtiva da pecuária de corte brasileira. Embrapa Gado de Corte-Capítulo em livro científico (ALICE). 8 edições. Brasília-DF, p. 117-130, 2019.

Medeiros, J. A. V., CUNHA, C. A. \& Wander, A. E. (2015). Viabilidade econômica de sistema de confinamento de bovinos de corte em Goiás. In Embrapa Arroz e Feijão-Artigo em anais de congresso (ALICE). In: Congresso da sociedade brasileira de economia, administração e sociologia rural, 53., João Pessoa. Agropecuária, meio ambiente e desenvolvimento: anais. João Pessoal

Nascimento, F. D. A. (2020). Confinamento de bezerros no período de transição secas-águas e seus efeitos sobre a recria e a terminação. Tese (Doutorado) Universidade Estadual Paulista (Unesp), Faculdade de Ciências Agrárias e Veterinárias, Jaboticabal, 2021.

NRC. (2001). Nutrient Requirements of Dairy Cattle. 7th rev. ed. Natl. Acad. Sci., Washington, DC.

Oliveira, C. A. \& Millen, D. D. (2014). Survey of the nutritional recommendations and management practices adopted by feedlot cattle nutritionists in Brazil. Animal Feed Science and Technology, 197, 64-75. https://doi.org/10.1016/j.anifeedsci.2014.08.010.

Oliveira, J. R. D. (2021). Recria de bovinos em pastejo recebendo suplementos com diferentes níveis de proteína durante período das águas. Monografia apresentada à UFT - Universidade Federal do Tocantins - Campus Universitário de Araguaína para a obtenção do título de Zootecnista, 2021.

Oliveira, P. H. P. (2019). Acompanhamento da recria à pasto de bovinos na Fazenda Guaicuí, Várzea da Palma-MG (Bache or's thesis, Brasil). Relatório apresentado ao curso de Zootecnia como parte das exigências para obtenção do grau de Bacharel em Zootecnia, 2019. 
Oliveira, T.E., Canozzi, M.E.A., Rocha, M.K, Teixeira, O.S. \& Barcellos, J.O.J, (2017). Desafios da pecuária do amanhã. Xii jornada Nespro e III simpósio internacional sobre sistemas de produção de bovinos de corte, 8., 2017, Porto Alegre. Anais de congresso, Porto Alegre: Universidade Federal do Rio Grande do Sul-UFRGS.

Pais, J., Fernandes, L., \& Minhoto, M. (2019). Análise técnico-económica da produção de vitelão Mertolengo DOP no centro de testagem e recria da Associação de criadores de bovinos Mertolengos. Actas Iberoamericanas de Conservación Animal: Revista Oficial de la Red Conbiand, v. 13 , p. 80- 89, 2019.

Paulino, M. F., Detmann, E., Valente, E. E. L., \& Barros, L. D. (2008). Nutrição de bovinos em pastejo. Simpósio sobre manejo estratégico da pastagem, 4(2008), 131-169. Viçosa, MG. Anais.

Pinto, A. C. \& Millen, D. D. (2018). Nutritional recommendations and management practices adopted by feedlot cattle nutritionists: the 2016 Brazilian survey. Canadian Journal of Animal Science, 99(2), 392-407. http://dx.doi.org/10.1139/cjas-2018-0031

Pinto, A.C. \& Millen, D. D. (2018). Recomendações nutricionais e práticas de manejo adotadas por nutricionistas de bovinos em confinamento: o levantamento brasileiro de 2016. Canadian Journal of Animal Science, 99(2), 392-407.

Razazzi, F. G. (2017). Estacionalidade da produção de leite em bacias de diferentes regiões brasileiras. Tese submetida como requisito parcial para obtenção do grau de Doutor em Ciências no Programa de Pós-Graduação em Zootecnia, área de concentração em Produção Animal.

Roth, M. T. P. (2019). Effect of supplementation level on performance of growing Nellore and its influence on pasture characteristics in different seasons. Ital J Anim Sci, v. 18, p. 215-225. ://doi.org/10.1080/1828051X.2018.1504633

Roy, B. C., Das, C., Aalhus, J. L. \& Bruce, H. L. (2021). Relationship between meat quality and intramuscular collagen characteristics of muscles from calffed, yearling-fed and mature crossbred beef cattle. Meat Science, 173, 108375. https://doi.org/10.1016/j.meatsci.2020.108375

Sá Souza, M., Jardim, A. M. D. R. F., Júnior, G. D. N. A., Silva, J. R. I., Leite, M. L. D. M. V., Teixeira, V. I. \& da Silva, T. G. F. (2018). Ciclagem de nutrientes em ecossistemas de pastagens tropicais. Pubvet, 12, 172. https://doi.org/10.22256/pubvet.v12n5a91.1-9

Salinas-Chavira, J., Barreras, A., Plascencia, A., Montano, M. F., Navarrete, J. D., Torrentera, N. \& Zinn, R. A. (2016). Influence of protein nutrition and virginiamycin supplementation on feedlot growth performance and digestive function of calf-fed Holstein steers. Journal of Animal Science, 94(10), 42764286. Doi: $10.2527 /$ jas2016-0576

Santos, F. G. R. (2018). Estratégias de diferimento das cultivares BRS PAIAGUÁS e BRS PIATÃ no semiárido brasileiro. Dissertação apresentada ao Programa de Mestrado em Zootecnia da Universidade Estadual Vale do Acaraú para obtenção do Título de Mestre em Zootecnia.

Santos, J. A. A. (2020). Estratégias adotadas na produção de bovinos de corte à pasto na entressafra. Trabalho de conclusão de curso apresentado para obtenção do grau de Zootecnista, junto Escola de Ciências Agrárias e Biológicas, da Pontifícia Universidade Católica de Goiás.

Santos, L. L. \& Borges, G. R. (2019). Fatores que influenciam no consumo de carne ovina. Consumer Behavior Review, v. 3, n. 1, p. 42-56.

Santos, R. T. T. D. (2017). Metologias usadas para a avaliação do comportamento ingestivo em pastagem e em confinamento (TCC) Universidade Federal do Pampa Dom Pedrito.

Silva, G. P.; Contin, T. L. M.\& Santos, A. C. R. (2018). Custos de confinamento de bovinos de corte no município de Colômbia, SP. Revista iPecege 4(4):715. Colômbia/SP. Disponível em: . Acesso em: 20 mar. 2021. Doi: 10.22167/r.ipecege.2018.4.7

Silva, M. S. J.; Jobim, C. C.; Nascimento, W. G.; Ferreira, G. D. G.; Silva, M. S.\& Três, T. T. (2013). Estimativa de produção e valor nutritivo do feno de estilosantes cv. Campo Grande. Semina: Ciências Agrárias. v. 34, no 3, p. 1363-1380. Doi: 10.5433/1679-0359.2013v34n3p1363

Silva, V. L. (2020). Cana energia e produção de silagem como estratégia para alimentação animal. Revista Veterinária e Zootecnia, v. 27, p. 001-013. https://rvz.emnuvens.com.br/rvz/article/view/507/280.

Silveira, L. G. G., Piona, M. N. M., Mousquer, C. J., Gomes, R. S., Silveira, A. C. (2021). Sistemas de cria em áreas tropicais: desmama precoce. Revisão de Literatura. Revista Brasileira de Higiene e Sanidade Animal, 15(1). http://dx.doi.org/: 10.5935/1981-2965.20210011

Siqueira, M. (2018). Confinamento expresso: um estudo de caso na região norte do Mato Grosso. Trabalho de Conclusão de Curso (graduação) - Universidade Federal de Santa Catarina, Campus Curitibanos, Graduação em Medicina Veterinária, Curitibanos.

Souza, S.S. (2018). Suplementos múltiplos de baixo consumo para recria de bovinos em capim Aruana. Dissertação (Mestrado em Zootecnia) - Universidade Tecnológica Federal do Paraná, Dois Vizinhos.

USDA- Departamento de Agricultura dos Estados Unidos. (2017). Livestock and Poultry: World Markets and Trade. United States Department of Agriculture, Foreign Agriculture Service. https://apps.fas.usda.gov/psdonline/circulars/livestock_poultry.pdf.

Valle, E. R.; Pereira, M. A. (2019). Histórico e avanços do Programa Boas Práticas Agropecuárias - Bovinos de Corte (BPA) entre 2003 e 2019. Embrapa Gado de Corte, Campo Grande.

Zebeli, Q., Aschenbach, J. R., Tafaj, M., Boguhn, J., Ametaj, B. N.\& Drochner, W. (2012). Invited review: Role of physically effective fiber and estimation of dietary fiber adequacy in high-producing dairy cattle. Journal of dairy science, 95(3), 1041-1056. https://doi.org/10.3168/jds.2011-4421 